\title{
ON TO ACTION- BUILDING A DIGITAL ECOSYSTEM FOR KNOWLEDGE DIFFUSION IN RURAL INDIA
}

\author{
JAYANTA CHATTERJEE \\ Industrial Management Engineering Deptt. \\ Indian Institute of Technology,Kanpur,U.P. 208016,INDIA \\ E-mail: jayanta@iitk.ac.in \\ T.V.PRABHAKAR \\ Computer Science \& Engineering Deptt. \\ Indian Institute of Technology,Kanpur,U.P. 208016,INDIA \\ E-mail:tvp@iitk.ac.in
}

\begin{abstract}
Information and Communication technologies (ICT) have been used to deliver knowledge to support agriculture and rural livelihood (ARL) for over ten years now. Yet, in India today, use of ICT to support ARL remains at an early stage. Our survey in North Indian states shows that less than $10 \%$ of the Krishi Vigyan Kendras (Agricultural Science Centers) and other extension initiatives actively "use digital content" or "contribute digital content" for common use. Yet there are more than a hundred active ICT initiatives towards this end across the country. This paper investigates this intriguing gap. This research identifies the need for 'easier' knowledge flow mechanisms, information exchange, storage and retrieval mechanisms that can span language and literary barriers. This paper outlines an approach towards a self-managed knowledge organization in the ARL domain.
\end{abstract}

\section{Introduction}

Agricultural and food security policy makers clearly see the need for knowledge connectivity from the academic/research institutes to villages and then on to the world to close the loop so that the 'best' practices can enhance India's agricultural efficiency, create the "next" practices and create new avenues for rural livelihood. There is a national agenda for creating 'Knowledge centers' in every village. But the 'soft side' of this challenge needs more attention. There is no concerted effort to create a national agricultural knowledge repository in digital form which is alive and is nurtured daily through feeding, weeding, \& pruning- or enriched by interactive usage. Lot of good knowledge nuggets remain at local level and as unstructured information or tacit knowledge. This paper reports the need for creating and implementing tools, architecture and replicable processes to enable cross flow of knowledge ("Information + insight" linked by concepts and contexts), in the form of "open content" for agriculture and rural livelihood. This paper chronicles the application of social networking and experiments to build a digital ecosystem for UserCo creation and self-management of digital contents to support agriculture \& rural livelihood development activities in the hinterlands of Northern India. It highlights the need for developing an Ontology server and an Indian agricultural thesaurus in vernacular for semantic interoperability of digital content developed by different stakeholders in this domain. The paper then reports on field experiments and observations made through the 'Digital Mandi ' project (www.digitalmandi.net) in the Kanpur-Lucknow region of Northern India and findings that show a pathway to Information design for knowledge diffusion in rural India. The paper describes the research using the SAP-LAP methodology.

\section{Situation (S)}

In quantitative terms Indian agriculture made significant progress over the last 50 years. One can see quantum jumps in total production of most agricultural commodities in reports published by the Indian Council of Agricultural Research or the Ministry of Agriculture. From chronic shortage and famine conditions of late 1950's, India has become a successful and significant exporter of many food grains and agricultural produce. An excellent food securing buffer stock has been built. But as India approaches the new WTO regime and the vision of borderless and eventually frictionless trade in Agricultural produce, 
India is behind most developed nations, even behind its smaller neighbors in Asia, in terms of almost all the rural economy efficiency measure and yield measures. India is also a country with one of the longest distribution chain for most rural produce. For many typical agricultural produce while the farmer may receive less than ten cents per kilogram, the retail urban consumer may pay ten to fifteen times of that per kilogram. The reasons are many but many researchers (Singh, 2002, Bhatnagar \& Schware, 2000, Kaushik $\&$ Singh, 2004) have pointed out information asymmetry, lack of rapid knowledge diffusion as prominent root causes. Researchers, policymakers and experts have frequently claimed that Information and Communication technologies represent one of the most powerful tools in the struggle against poverty. These tools can enhance the efficiency \& effectiveness of Indian Agricultural practices \& processes, by generating newer inspirations and avenues for grass root rural entrepreneurs and innovators.

There are various private and public efforts to expand "information and communication" access in rural India. It is expected that telephones, mobile phones, broad band internet, cable, community FM radio and many other forms of coverage will rapidly expand connectivity and access over the next 10 years. Technologies will continue to get cheaper, easier to use.

The cost and challenges of the ICT interconnection for rural India is huge and it is receiving significant attention. But this is not the only problem. Extension services and other content providers in this domain face high cost to develop and maintain digital resources. Often content is kept offline to protect print sales or may be accessible only at a fee.

The content that is online and free, is often not updated regularly, uncoordinated with other providers, so there is lot of duplication of general information and not enough 'specific' local information, making "pertinent content" harder to find.

Content that is live, interesting and 'in depth', interesting databases and decision- tools remain rare. This 'knowledge' side of the "digital divide" must be addressed as vigorously as the "access" side. Bolstering this activity may even speed up access infrastructure as the farmers \& rural folks will then enhance the 'pull' effect to complement the current policy 'push'. While there are many variables that need to come together to enhance productivity in Indian rural livelihood \& agricultural activities, which may not be entirely controllable, we can at least facilitate knowledge creation \& knowledge exchange to help rural citizens deal successfully with unforeseen variables.

\section{3. $\operatorname{Actor}(\mathbf{A})$}

The challenges before Indian Agriculture are immense. This sector needs to grow at a faster rate than in the past to allow for higher per capita income and consumption. It is an accepted fact that the sound agricultural development is essential for the overall economic progress. Two thirds of Indian workforce directly or indirectly depends on agriculture. This sector generates about 28 percent of its GDP and over 15 percent of exports. Rising consumer prosperity and the search by farmers for higher incomes will simultaneously drive crop diversification. Export opportunities for agricultural products are also expected to continue to grow, provided India could meet the stability, quality and presentation standards demanded by foreign trade and consumers and maintain its comparative advantage as a relatively low cost producer. (Source: Kisan Call Centre website)

Given its range of agro-ecological setting and producers, Indian Agriculture is faced with a great diversity of needs, opportunities and prospects. The well endowed irrigated areas which account for 37 percent of the country's cultivated land currently contribute about 55 percent of agricultural production, whereas, rain fed agriculture which covers 63 percent of land accounts for only 45 percent of agricultural production. In these less favorable areas, yields are not only low but also highly unstable and technology transfer gaps are much wider as compared to those in irrigated areas. This is where knowledge can play a significant role to manage the critical challenge of rural poverty.

If India is to respond successfully to these challenges, greater attention will have to be paid to technology. Strengthened means of dissemination will be needed to transmit cutting edge know-how \& 
information to farmers and rural artisans. Both technology generation and transfer will have to focus more strongly than ever before on the themes of optimization in the management of the available resources by producers, sustainability, coping with diversity by adapting technology more specifically to agro-ecological or social circumstances and raising the economic efficiency of agriculture. To make information transfer more effective, greater use will need to be made of modern information technology and communication among researchers, extension professionals and farmers. (Source: NATP website)

Public extension system requires a paradigm shift from top-down, blanket dissemination of technological packages, towards providing producers with the knowledge and understanding with which they solve their own location - specific problems. Continuous two-way interaction among the farmers and agriqultural seientists is the most eritical missing eomponent of Agrieultural Exfension.

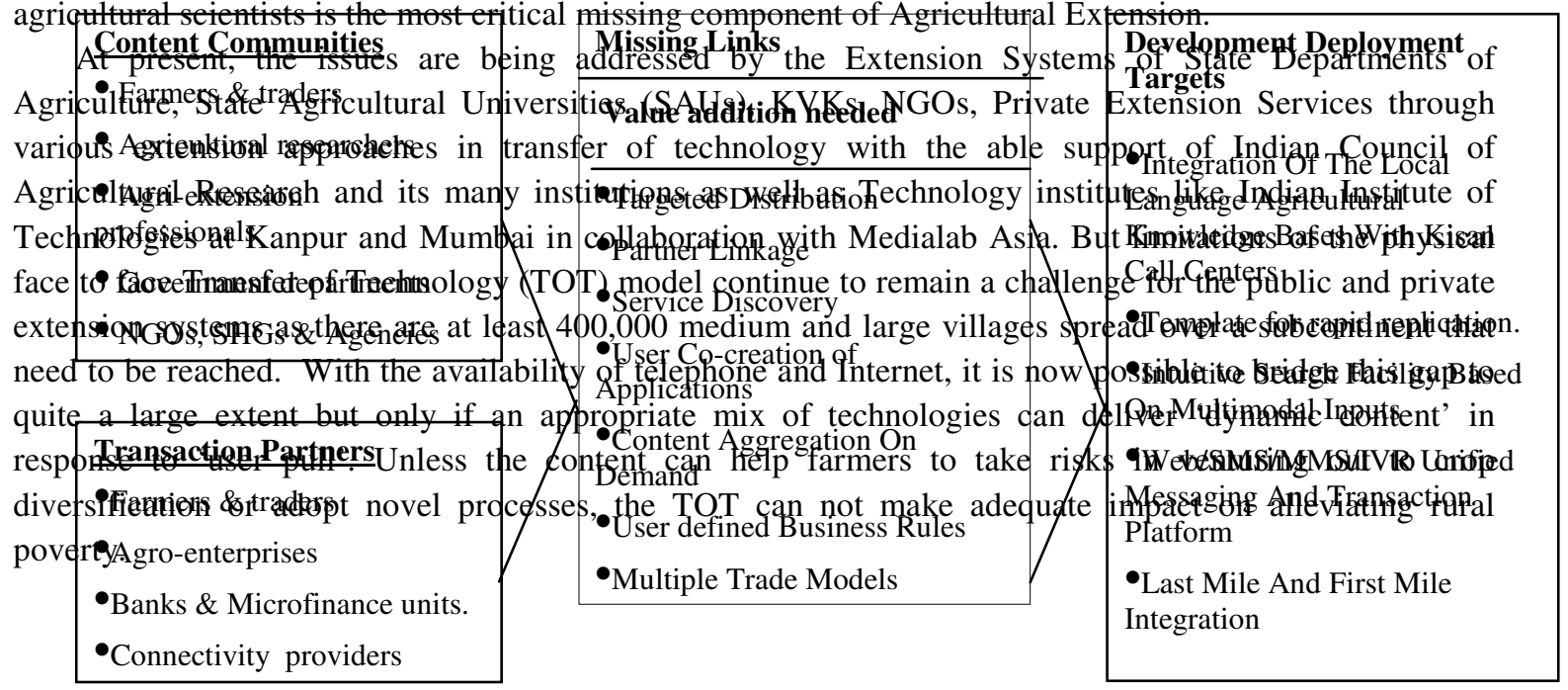

Figure I- Missing links in a network of stakeholders

There are many efforts today by a number of stakeholders (figure I) to address these issues in government, Institutional and private sectors. However most of these efforts depend on project funding from the government and the business models for 'content' generation and 'digital repository' efforts in vernacular languages are not self-sustaining. Yet, valuable contents are generated everyday in the Indian agricultural domain through the physical interaction between scientists at KVKs and rural citizens. However, in absence of a commonly agreed Ontology, metadata and other conceptual standards and in the absence of "easy to use" electronic interface and electronic exchange these physical contents remain tacit and do not contribute to a commonly accessible knowledge repository. Policy makers want to set up a virtuous cycle of learning - innovating -implementing- evaluating and learning again for agricultural and 
rural development. But in a large democratic country like India, the process involves many stakeholders and many actors. Figure 2 shows the information flow diagram for rural development activities. It is obvious that an ontology driven semantic interoperability through this maze can effectively network the different actors, while they pursue their micro objectives.

(1) Consolidated Progress Reports

(2) Consolidated Annual Plans

(1) Consolidated Progress Reports

(2) Consolidated Annual Plans

(1) Consolidated Progress Reports

(2) Consolidated Annual Plans

(1) Progress Reports (Physical \& financial)

(2) Annual Plans

(1) Details of loan/subsidy utilized, details of achievement of intended benefits (infrastructure, housing, income generated etc.)

(2) Needs/Requirements etc.

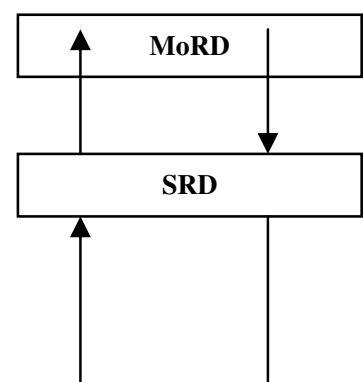

(1) Details of fund allocations, sanctions, scheme guidelines by GoI

(1) Details of Fund Allocations, sanctions, scheme guidelines by State Govewrnment

(2) Details of distribution of funds allocated/sanctioned by

GOI, GOI scheme guidelines

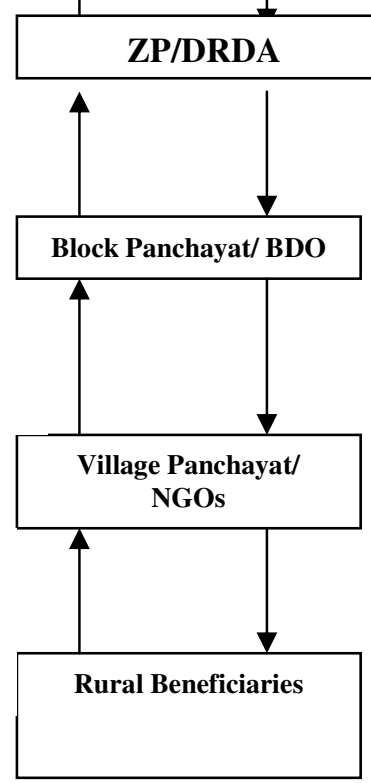

Details of distribution of funds allocated/sanctioned by GOI/ State Govt. , scheme guidelines

Details of distribution of funds allocated/sanctioned by GOI/ State Govt., scheme guidelines etc.

Details of beneficiaries (village, group, family, individual) selected, benefits (employment, houses, roads etc.) funds (loan, subsidy etc.) available etc.

Figure 2: Typical flow of information among rural development agencies (Source: CRISP group, National Informatics Center)

\section{Problem}

Longitudinal discussions with extension workers, agricultural experts, researchers, NGO's and detailed analysis of 83 websites or portals which belong to Krishi Vigyan Kendra's, Government departments, Agri Universities, Institutes and many web pages relating to Indian Agriculture hosted by global bodies (App. I), indicate the following requirements for a successful implementation of the knowledge system:-

1. Development of digital content from the tacit knowledge bases of KVKs \& other frontline entities should be possible through multiple media like landline phone, mobile phone, audio-video recording and digitization of paper documents.

2. Developing a common ontology, a semantic interoperability that facilitates knowledge storage, retrieval and exchange within the network among the various stakeholders so that a knowledge ecosystem can develop.

3. Open content and open source optimization so that the technology tools are affordable and remain available while evolving.

4. Developing "citizen interfaces" to the extensive knowledge base. These could be iconic, graphical, symbolic user interfaces (that relate to the ontology) for rural citizens' ease of access. 
This will include but not limited to application of touch screen, text to speech, screen reader, visualization \& animation, interactive voice response system computer-telephony integration and application of wireless data services like MMS.

5. Digital content architecture and tools for easy telephone, mobile data and FM radio based interactivity and backend integration of such transactions into the knowledge base.

\section{Learning (L)}

There are a number of ways - some obvious and some not-so-obvious ones - in which ICT may serve the development process. For instance rural entrepreneurs can benefit because ICT help to improve access to markets or supply chains and provide a broader base for decision-making, thus making risk more calculable. Moreover, many local communities have experienced that ICT have increased bottom-up participation in the governance processes and may expand the reach and accessibility of government services and public infrastructure. In Andhra Pradesh or Karnataka Internet-based Citizen Service Centres allow for electronic bill payment, issuing of land record certificates, permits and licenses; or access to public information. The electronic village project of M.S. Swaminathan Research Foundation (MSSRF) in Pondicherry received the Stockholm award for its promise.

However, there is as yet little systematic empirical evidence of the supposed enormous 'developmental' impacts of ICT. Moreover, in many - especially rural - areas, the private sector is yet to invest significantly in ICT experiments (except for a few pioneers). This means that, if ICT access is to be expanded, public money will have to be spent - which in turn means that there are important trade- offs to be considered. In many areas, there are serious questions about how much money policymakers should spare for the build-up of ICT instead of investing further in potable water supply, roads, electricity or other physical infrastructure projects.

Given such trade-offs, there is a need to identify which kinds of ICT access and content deliver the best value for money, and how the limited resources that can be spent on it can be made to best suit the particular needs of rural India. A number of 'models' have so far been tried around the world.

One popular model of ICT provision in rural areas of developing countries, and one which attempts to combine phone access with access to the Internet. These are the so-called Telecentres or Information Kiosks or the recently introduced Infothela of Media Lab Asia- Kanpur-Lucknow Hub (www.iitk.ac.in/MLAsia). An Infothela is a common point of access for multiple users (often an entire community), providing a range of ICT services including Internet, fax, phone, e-mail, word processing, and even specialized information retrieval or applications for agriculture \& rural livelihood.

Telemeters have been established widely in the developing world, and vary in their service provision and means of funding. In Peru, the establishment of numerous 'Cabañas Públicas' created one of the highest concentrations of public Internet access and a significant reduction in prices. Nevertheless, the experience with telemeters has so far been a mixed one. In numerous cases, usage, particularly of PCs, has been lower than expected or commercial viability was not attained. Of the over 70 Community Telemeters established since 1997 by the South African Universal Services Agency, only 40 per cent remain open today, with only 3 per cent making enough money to cover costs.

Buried at the end of the World Bank policy paper on the 'Networking revolution: opportunities and challenges for developing countries' (June, 2000) is an account of multipurpose community telemeters (MCTs) in rural Mexico. It turns out that of twenty-three MCTs built in rural Mexico; only five were working two years later. This is a failure rate of 80 percent.

The policy paper comments, "Problems encountered included insufficient maintenance funding, inadequate political interest and will, and cultural constraints which hamper community interest in the projects." The paper gives no hint why "political interest and will" might have been inadequate and why community interest might have been constrained by that hold all excuse for failure, "culture." The paper concludes that the Mexican case "underscores the importance of participatory design and attention to sustainability issues in the development of such programs." This problem was identified as a key research agenda for the Digital Mandi (www.digitalmandi.net) project, which stimulates this report.

Internet and Information Kiosks exist in various kinds, each with their respective merits. First, one might distinguish between the small private sector cyber cafes on the one hand and bigger, donor-funded 
telemeters like e-Seva in Andhra Pradesh or e-Village in Pondicherry on the other hand. Smaller, privately run cyber cafes are often financially self-sustaining - but are thus usually restricted to areas where they expect to be viable (usually urban centers) and are usually neither within physical nor financial reach of the poor. They are also unlikely to be able to provide local content. - By contrast, larger, often externally funded telemeters are rarely financially sustainable but can focus more on specific 'development' - aspects, including access. They can be specifically targeted at rural communities and can focus on training and knowledge diffusion.

A second distinction is according to the institutional context they are embedded in. This often has a significant influence on the 'developmental impact' of telemeters. Commercial telemeters and commercial franchises are usually closest to commercial viability but, as mentioned, are unlikely to have an impact on the poor outside the economic circle. Telemeters run by or with the involvement of developmental NGOs are more likely to target poor and marginalized communities and focus on much-needed additional services like training, content creation, provision of public goods without which ICT access would be of limited developmental use. Telemeters in rural institutes, village schools or Krishi Vigyan Kendra's for example as another alternative have the significant advantage that for their establishment an existing physical infrastructure only has to be extended and some of the ICT-relevant training can be cost-effectively integrated into the mainstream curriculum of these institutions. This partnership has successfully worked in the Digital Mandi project (www.digitalmandi.net).

\section{Action (A)}

Thus there are a number of alternatives and apparently mutually exclusive business models for ICT implementation in Rural India.

On one hand it appears that kiosks run by local entrepreneurs with localized and targeted applications will succeed on the other hand following the success model of the world wide web itself one may suggest that if an infrastructure is created and user friendly appropriate interfaces are continuously accessible then local rural folks will develop their own applications and Information Kiosks or Infothela will survive.

But there are serious barriers that impede the later possibility. Barriers to information access may be physical, economic, intellectual or technological, that impede rural users participation in the activities that add to the digital knowledge repository. The barriers may be actively imposed by the architects and system designers or they may be allowed to continue simply through their lack of action or lack of understanding of the critical user conditions. Such critical user conditions may arise due to particular demographic, geographic, cultural, social, psychological, economic or other factors. Issues related to Information system usability such as ease of use, usefulness (Davis, 1989), decision effectiveness (Mason et al, 1973), user response, user satisfaction (Doll et al, 1988) and many other aspect of usability have been studied in great detail by researchers. But interactions with focus groups at various agricultural market places around Lucknow-Kanpur showed the need of a more detailed study on Information communication barriers on a more localized set of priorities.

A general framework for web design keeping in mind the human-computer interaction theories (Pirolli, 2001), web site usability principles (Huang, 2003), information intensity paradigm (Palmer and Griffith, 1998), e-customization models (Ansari and Mela, 2003) is already in place and is assumed to sufficiently address the question of defining broad guidelines for designing any successful website. It is therefore, assumed that a website with relatively high-level of accurate, up-to-date and pertinent content, deployed in a user-friendly way, customized to particular user groups, and tailored to specific geographical needs should be universally successful and hence, accepted in India too. However many such efforts have apparently failed to achieve their targets.

The challenges to agricultural and rural livelihood website usability for rural India arise mainly due to the highly specific local needs and the great diversity in local conditions. The major challenges are:

- Poor literacy rate - low use of textual information in daily life and high reliance on verbal communication for knowledge transfer. 
- Remote village locations - physical distances compounding problems of dependence on middlemen and a nexus of exploitation through information asymmetry.

- Absence of content in vernacular languages (both a cause and an effect)

- Economic, low-cost solutions - any technology solution aimed at benefiting the masses in rural India must be affordable and low-cost so that the perceived economic benefits of such an endeavor are much more than the cost of switching over to a different technological solution.

A model that inspired the Mandi team was The Kothmale Community Radio in Sri Lanka. This project has combined community radio and Internet access. It has a leased line connection to the Internet and in the so-called process of 'radio browsing' Programme presenters browse the Web in the studio on behalf of listeners (who provide requests/input through phone or post). Relevant 'experts' from the community then interpret the information for listeners. Another good example of the creation of relevant local content is the 'Infoshops' in Pondicherry, India. After information requirements are identified during a trial period, volunteers from the village create a local database comprising government programs for low income rural families; cost and availability of farming inputs such as seeds and fertilizers, grain prices in different local markets; a directory of insurance plans for crops and families; pest managements plans for rice and sugar cane; a directory of local hospitals, medical practitioners and their specialties; a regional timetable for buses and trains; a directory of local veterinarians, cattle and animal husbandry programs. All these preceding experiments contributed to the Digital Mandi design. But the project soon revealed that without a self managed, evolving, ecosystem like knowledge repository, where users can co-create content and the content can be so "tagged" that it can be recalled and reused in multiple context, the editorial over head remains high \& expensive.

\section{Performance $(\mathbf{P})$}

The finding from the initial research at Digital Mandi has shown that the presence of a number of desired features in any ICT system design for rural India that leads to higher user satisfaction. Such features are broadly aimed at satisfying one or the other of the following immediate user objectives:
a) Ease of access.
b) Up-to-date content.
c) Layout, design, consistent themes.
d) Easy navigation.
e) Higher interactivity.

f) Access through multiple media (particularly voice).

g) Higher use of non-textual information.

h) Language options

i) Lower cost of transaction.

Figures A and B in the Appendix show the resultant implementation techniques reported earlier (Chatterjee, 2003).

The Digital Mandi project thus revealed that ICT tools and technologies can make knowledge and field experiences (in the form of digital content) widely available. Ethnographic observation guided design principles, which improved access and acceptance by rural citizens. But the maintenance, dynamic update and enhancement of the digital content needed regular editorial intervention and the process of finding and assembling information remained largely a manual task.

Several brain storming sessions of the stake holders in the Digital Mandi project generated a conceptual architecture of the desired knowledge-net. 


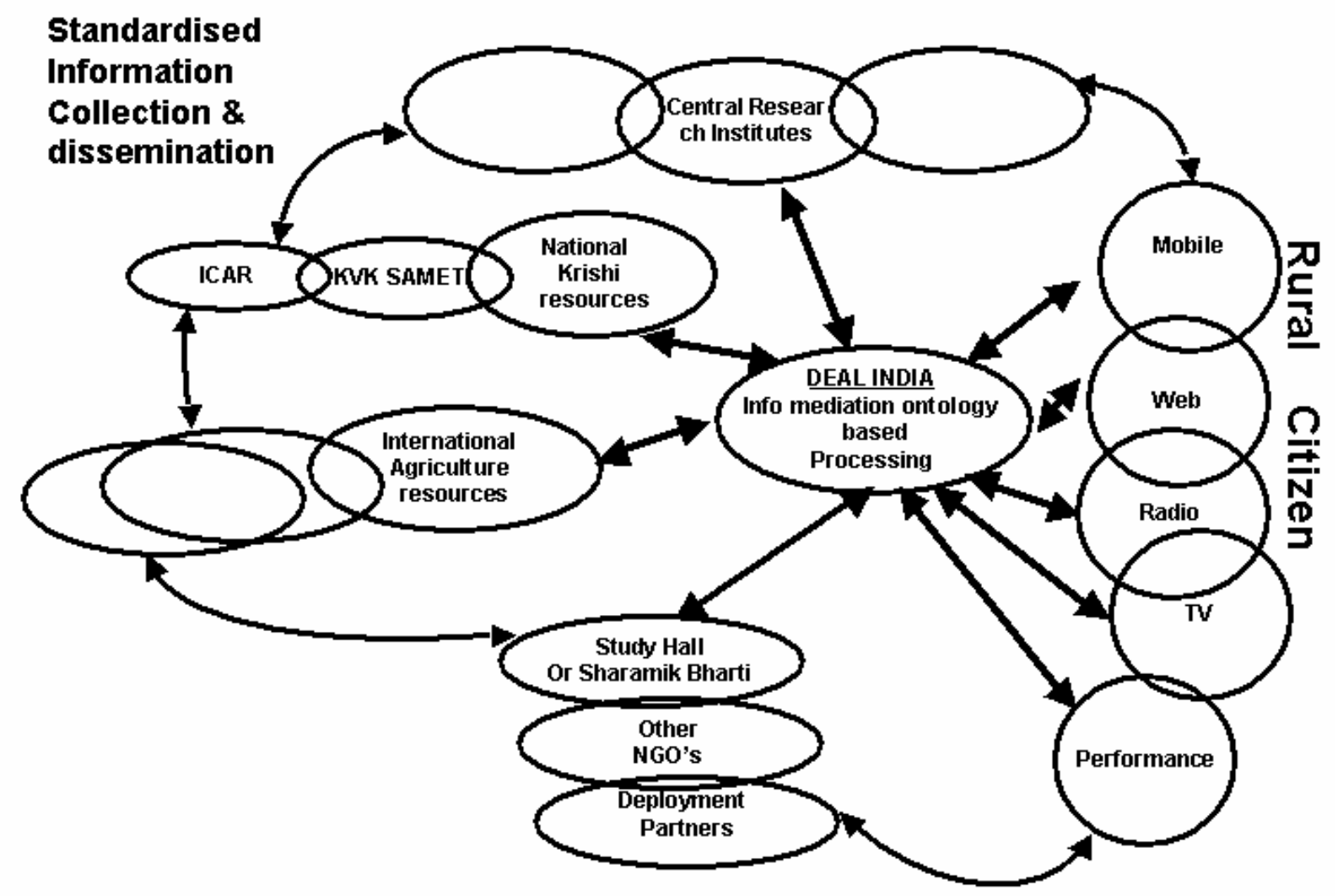

Figure 3: Conceptual architecture of knowledge-net

This is shown in figure 3.It was clear that to acquire the characteristics of a self-managed ecosystem, in this knowledge-net, the digital contents created in various forms by the stakeholders needed 'interoperability'. Interoperability provides potential for automation and systemic self-management. Initial experiments across the digital repositories of the stakeholders in the project showed that syntactic interoperability can be achieved for transfer, exchange, mediation and integration of content by adopting compatible forms of encoding and access protocols and design guidelines. Identification and naming schemas are important at this stage for pulling together related information. But while that operability may be enforceable in a corporate extra-net, in the domain of ARL it poses many problems due to the diversity of stakeholders and multiplicity of hardware/software and other socio-technical diversities existing in the network.

The goal framework in the next phase of the project thus focuses on semantic interoperability. The goal here is to facilitate context sensitive query processing over heterogeneous information sources.

The current phase of this research project therefore focuses on developing an Ontology server (OS) in the Indian ARL domain (IARL). The agenda here is to build an action oriented vehicle to provide consistent usable access to information for the rural Community searching for knowledge, as well as to assist those whose interaction (e.g. KVK scientists and farmers) create new knowledge. Firstly, the project now attempts to build the OS for IARL as a reference tool that can structure and standardize agricultural terminology in multiple Indian languages for use by different systems. This ontology will contain terms, the definition of those terms and the specification of relationships among those terms. It will start with a Thesaurus, the conversion of the Agrovoc hosted by the Food and Agriculture Organization of the United Nations in Hindi \& later in other Indian language. But the aim is to work in parallel on enhancements to the 
Thesaurus, so that the system can provide the basic relationships inherent in the thesaurus. It will aim to capture and structure the knowledge in the ARL domain. Figure 4 depicts select dimensions of the technology framework for this ontology driven approach to rapid deployment of laboratory knowledge for field level actions.

Figure 3 and 4 together represent several parallel sets of activities that are being pursued within a project framework that has been called DEAL- Digital Ecosystem for agriculture and rural livelihood support. Key clusters of these activities are:

I. Developing a Thesaurus in Hindi based on United Nation FAO's Agrovoc as a first step. Thesaurus in all other major Indian Languages will follow. This entails consensus building among different regional subcultures and agricultural practices.

II. Development of taxonomies, data models and ontologies for collating, searching and aggregation of agricultural content.

III. A range of easy to use interfaces for acquiring the knowledge exchange between the extension workers and the farmers from the field through voice mail, email, web log, sms, mms, photographs, video recording and even paper documents. New collaborative authoring, co-creation tools are being developed that facilitate non-textual aggregation.

IV. Intuitive UI, novel metaphors for contributing, accessing, searching and composition of knowledge objects from the field, development of metrics to monitor usage and impact.

V. Content inputs and content delivery happen over multiple platforms, the key challenge is to manage the back end integrity, easy access but high security.

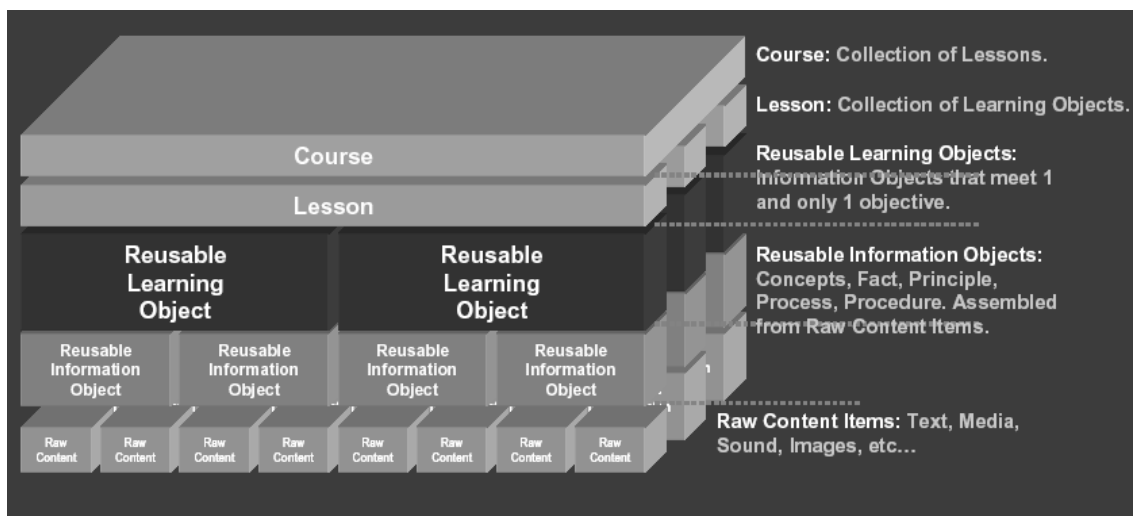

Figure 4: Ontology driven knowledge exchange implementation

\section{Conclusion}

Rapid knowledge diffusion is a critical need for building up the global competitiveness of Indian agriculture. Low level of textual information usage and multiplicity of languages in the learning network of knowledge creators and knowledge users demand novel interfaces for knowledge capture \& exchange. But the research project running for nearly 3 years now has a core focus on the knowledge organization system in the form of an ontology driven service because that is the only way to make the vast task of creating a digital knowledge repository, to a large extent, self-managed. The Indian agricultural ontology server will thus be at the core of the nascent digital ecosystem. However there are significant other research outcomes regarding information design both in terms of architecture and content presentation for this federated knowledge service. 


\section{Bibliography}

Bhatnagar, S. and Schware, R. (2000) "Information and communication technology in develpement, cases from India", New Delhi, Sage Publications.

Card S.K., Robertson G.G. and Mackinlay J.D. (1991) "The Information Visualizer: An information Workspace", $C H I$ '91, New Orleans

Chatterjee, J. (2004) "Information communication and e-Marketing in rural India- learnings from the Digital Mandi project" in Haleem, A. (Ed) Innovation, flexibility and technology transfer, Tata Mcgraw Hill, India.

Chan Y.E.(2000) "IT value: The great divide between qualitative and quantitative and individual and organizational measures", Journal of Management Information Systems 4, 225.

Claudia D. (2001) "Corporate portals: a literature review of a new concept in Information Management", International Journal of Information Management, 21, 269-287

Constant G., Jean-Pierre H., Giovanni P. and Asser N. T. (1998) “An Architecture for the Integration of Internet and Telecommunication Services", Technical Report SSC/1998/025. Available from http://sscwww.epfl.ch/

Davis F. (1989) "Perceived usefulness, perceived ease of use and user acceptance of information technology", MIS Quarterly 13(3), 319-340.

Doll W.and Torkzadeh J.(1988) “The measurement of end-user computing satisfaction", MIS Quarterly 6, 259-273,

Hooker N.A., Heilig J.and Ernst S.(2001) "What is Unique About E-Agribusiness?", IAMA World Food and Agribusiness Symposium, Sydney, NSW, Australia

Huang W.(2001) "Using Information Technology to Enhance Communications among Agribusiness Organizations", IAMA World Food and Agribusiness Symposium, Sydney, NSW, Australia

Huizingh E.K.R.E. (2000) "The content and design of Web sites: an empirical study", Information \& Management 37, 123-134.

Kaushik, P.D. and Singh, N., (2004) "Information technology and broadbased development" in (Ed.) Singh, N., Information technology and rural development in India Sage Publications Delhi

McMillan S.J., Hwang J., (2002) "Measures of Perceived Interactivity: An Exploration of the Role of Direction of Communication, User Control, and Time in Shaping Perceptions of Interactivity", Journal of Advertising, 3, 29-42

Mueller R.A.E, (2001) "Impacts of E-Commerce and Information Technology on Global Agricultural Markets", Symposium sponsored by the Economic Research Service, Farm Foundation and the University of Minnesota, Washington, DC

Palmer J.W. and Griffith D.A., (1998) "An emerging model of website design for marketing", Communications of the ACM 41(3), 44-51.

Palmer J. W., Griffith D. A., (1998) "Information Intensity: A paradigm for understanding web site design”, Journal of Marketing Theory \& Practice, 6 (1), 38-42

Palmer J.W., (2002) "Web Site Usability, Design, and Performance Metrics", Information Systems Research, 13 (2), 151-167

Pirolli, P., Card S. K. and Van der Wege, M. (2001) "Visual Information Foraging in a Focus+Context Visualization", CHI 2001, Seattle

Schiefer G.(July 2003) "New Technologies and their Impact on Agriculture, Environment and the Food Industry", EFITA 2003, Debrecen, Hungary.

Singh, N (2002) "Information technology as an engine of broad based growth in India", in The information economy in India, (Ed) Parthasarthi Banarjee and Richter FJ, London, Palgrave/ Macmillan. 


\section{Appendix}

\begin{tabular}{|l|l|}
\hline ICAR INSTITUTES & $\begin{array}{l}\text { ICAR, IARI, CICR, CAZRI,CIRG, NBAGR, NBPGR, CIAE, IASRI, NCAEPR, IIVR, IIPR, NIRJAFT, } \\
\text { VPKAS, NDRI, IIHR, NIANP, NRCOG, NCIPM, PDBC, IISR(SPICES), IISR(SUGARCANE), IISS, } \\
\text { NRCM, NRCMAP, AICRPM }\end{array}$ \\
\hline STATE & $\begin{array}{l}\text { MPKV, RAHURI; PDKV, AKOLA; PAU, LUDHIANA; HAU, HISAR; KAU, THRISSUR; TNAU, } \\
\text { AGRICULTURAL } \\
\text { COIMIVERSITIES }\end{array}$ \\
\hline MINISTRY OF AGRI & NIAMALORE; GAU,NAVSARI; AAU, JORHAT; TANUVAS, CHENNAI; UAS, DHARWAD; UAS, \\
\hline \hline
\end{tabular}

Table I: Major Oranisations with Websites on Indian Agriculture

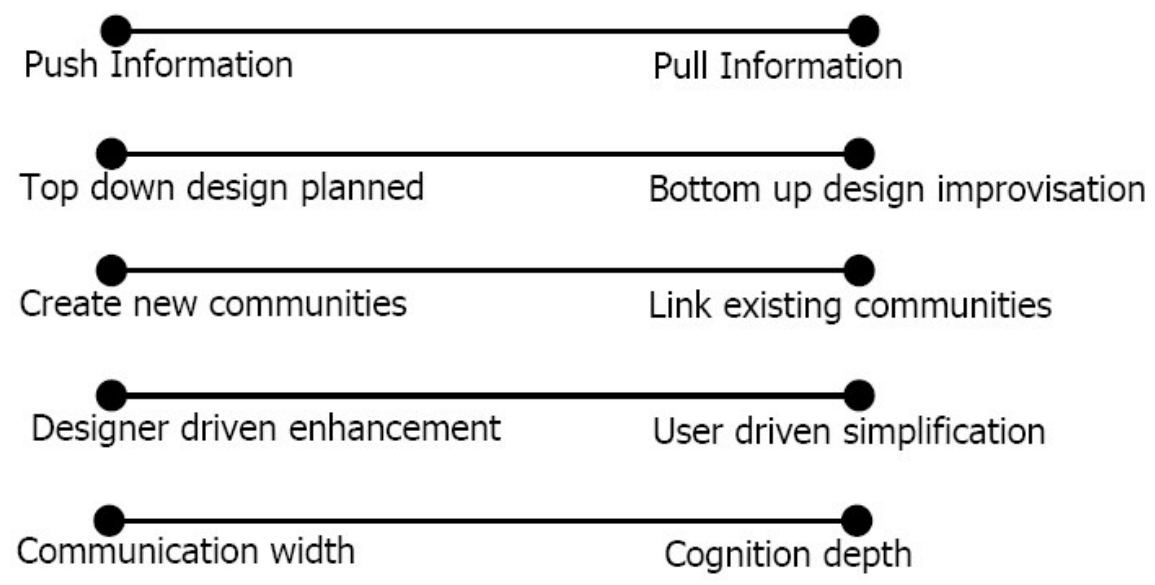

Figure A . Flexibility Continuum Of ICT Diffusion Models

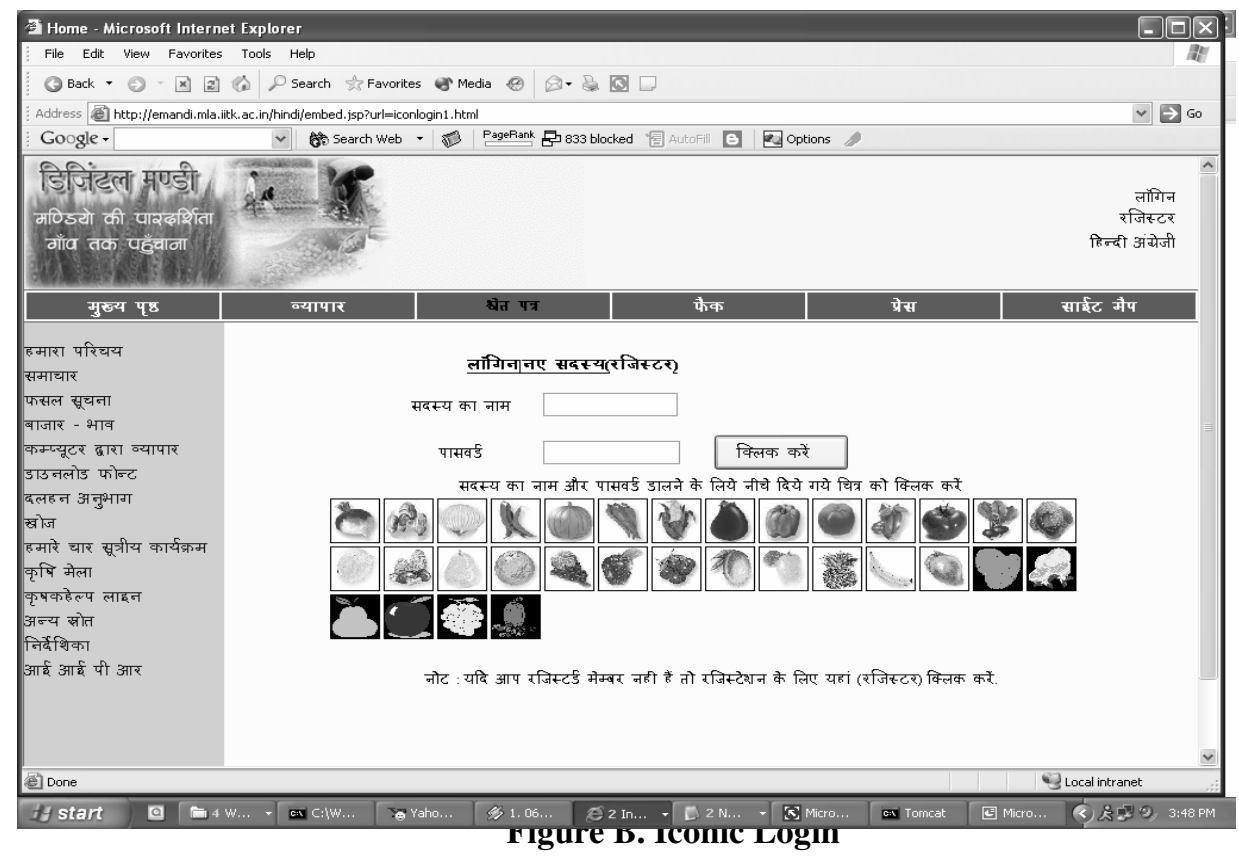

